\title{
Dynamics of family households and elderly living arrangements in China, 1990-2010
}

\author{
Yi Zeng ${ }^{1,2} \oplus \cdot$ Zhenglian Wang $^{3}$
}

Received: 18 April 2018 / Accepted: 15 June 2018 / Published online: 10 July 2018

(c) Springer Nature Singapore Pte Ltd. 2018

\begin{abstract}
This article presents analyses on dynamics of family households and elderly living arrangements in China mainly based on the micro data of 2010, 2000 and 1990 censuses. We demonstrate and discuss the trends and rural-urban differentials of largely declined household size, quickly increasing one-person and one-coupleonly households, substantially increased proportions of elderly living alone or with spouse only. It is strikingly interesting that proportion of three-generation family households increased by $18.9 \%$ in rural area but decreased by $23.7 \%$ in urban areas in 2010 compared to 1990 , due to rural-urban differences in demographic effects of large fertility decline and socioeconomic/attitude changes. We also present and discuss two interesting demographic phenomenon which were relatively overlooked in the literature. First, increase in number of households is much larger than population growth, due to shrinking of the household size and decomposition of larger families into smaller ones, and very much slowed-down population growth. Second, increases in numbers of elderly (especially oldest-old) who live alone or with spouse only are dramatically larger than the increase in the corresponding proportions, due to the effects of rapid population aging, while later and larger birth cohorts become old. Such trends have important implications for the analyses on the current and future market demands of the products and services, of which households are the consumption units. We recommend that the studies on home-based energy use and sustainable development should be based on analyses of family household dynamics rather than population growth.
\end{abstract}

Keywords Dynamics of family households · Elderly living arrangements $\cdot$ Shrinking household size $\cdot$ Increasing number of households $\cdot$ China

Yi Zeng

zengyi@nsd.pku.edu.cn

Extended author information available on the last page of the article 


\section{Introduction}

Under the rapid socioeconomic transformations, which have been taken place in China over the last several decades, how have the Chinese family households and elderly living arrangements changed? How can we better understand these dynamic changes? Our previous studies based on the one-per-thousand micro sample data from 1982, 1990 and 2000 censuses of China have shown that, during the period of 1982-2000, the one-person and one-couple-only households have been increasing quickly; average household size decreased significantly; the proportions of elderly-couple only households and elderly who did not live with children substantially increased (Zeng and Wang 2003). Other studies also had similar findings and concluded that the family transformation in China during the period 1982-2000 was caused by factors including the tremendous fertility decline, rapid industrialization, increasing migration, rise in women's education, and the significant changes in social attitudes and economic mobility related to co-residence between old parents and adult children (Wang 2006; Guo 2008; Fan 2002; Cheung and Yeung 2013).

The most recent census of China in 2010 reveals that the trends outlined above have continued. For example, although the total number of households continues to increase in China, the average household size reduced from 3.44 in 2000 to 3.09 in 2010; in particular, small households with only one or two persons have increased rapidly (Zhou 2013). With regard to the household structure, Wang (2013) found that the nuclear households, the three-generation stem family households, and the one-person households make up the majority of the Chinese household in 2010. Among these three major types of households, the proportion of three-generation stem family household remain stable in recent decades, whereas the proportions of the nuclear family households has significantly declined in 2010 as compared to 2000 due to the rapid increase of the oneperson household. Hu and Peng (2014) and Cheung and Yeung (2013) pointed out that the young rural immigrants to urban areas could have contributed to the growth of one-person households in both rural and urban areas: the inflow of young immigrants increase the one-person household in cities; simultaneously the left-behind elderly parents in rural area contribute to the increase of one-person elderly household in the rural regions. With regard to elderly living arrangements, the increase in the proportion of elderly aged 65 or over who live alone or with spouse only and the decrease of the proportion of elderly living in threegeneration stem family households from 1982 to 2010 are very substantial (Wang 2014; Zhang 2013).

Based on our own and others' previous studies, this article intends to make some significant contributions to better understanding of dynamics of households and elderly living arrangements in China. We conduct comparative analyses across different periods as well as rural and urban areas, based on analysing the micro data files of the 2010, 2000, and 1990 censuses in combination with the officially published $100 \%$ cross-tabulations. We integrate the analysis of elderly living arrangements with the family household dynamics in this article because 
Chinese population has been aging rapidly (Banister et al. 2010) and family is the most important institution for old-age support in Chinese society (Pei and Pillai 1999; Chen and Silverstein 2000; Yeung and Xu 2012). We will investigate the trends and patterns based on not only dynamics of proportion distributions of the household types/sizes and elderly living arrangements but also changes in the absolute numbers, which are useful for socioeconomic planning and business/ market analyses. The next section outlines the data sources and the approach of analyses. The third and fourth sections present the general patterns and dynamic changes of family household sizes and types as well as the living arrangements of the elderly since 1990. The fifth section discusses the rural-urban differentials. Throughout the paper, we will also discuss socio-economic and cultural explanations on the patterns and dynamic changes in Chinese family household and elderly living arrangements.

\section{Data sources and the approach of analyses}

The analyses presented in this article are mainly based on the micro sample data of the 2010, 2000, and 1990 censuses with a sample size of 1.34, 12.6 and 1.14 million persons, respectively (the sample fraction was one-per-thousand of the total population for 2010 and 1990 censuses and one-per-hundred for 2000 census). ${ }^{1}$ Based on analyzing the 1953, 1964, and 1982 censuses data and the 1982 one-per-thousand fertility survey data, Coale (1984) concluded that the data passed a series of stringent tests of accuracy and consistency. Other scholars who have analyzed Chinese censuses and survey data have reached similar conclusions (Kannisto 1986; Lavely 2001; Cai 2013). Underreporting of births has, however, become a problem in recent decades contributing to underestimation of not only fertility but also family household size. Based on sophisticated demographic analysis using the censuses and various other kinds of data, many scholars demonstrated that the overall fertility in China (especially in urban areas) has been far below the replacement level since the late 1990s (Zhang and Zhao 2006; Zhao and Chen 2011), and thus the effects of underreporting of births on statistics of magnitude of family household size may not be very large. Statistical officers and scholars in the field generally believe that census enumerations had become more difficult in the process of radical market economic reform mainly because many more people were moving around and the administrative system was not yet adapted to the tremendous changes. For example, based on post-census sampling surveys, the officially published net undercount rate of the 2000 census was $1.81 \%$, in contrast to $0.6 \%$ in the 1990 census. However, the officially reported net undercount rate in the 2010 census was $0.12 \%$, largely reduced compared to 2000 and 1990, perhaps due to the more mature administrative system adapted to the

\footnotetext{
${ }^{1}$ Because of the huge sample size of the census micro data and we only use the aggregate measures in this article, we believe that it may not be necessary to perform statistical tests for evaluating the differentials across periods, sex, broad age groups of younger elderly and the oldest-old and rural-urban sectors.
} 
market economic system (Cui et al. 2013). In general, the undercount rates in the contemporary Chinese censuses are not very high as compared to other countries (Zhao 2011). Nevertheless, we must keep the issue of undercount rate in mind, although it may not significantly affect our analysis on family household types and living arrangements of elderly who usually do not move around.

Note that the governmental socioeconomic planning and private business market analysis need not only detailed proportions distributions but also absolute numbers of households by types/sizes and elders by living arrangements. In some circumstances, the dynamic changes in absolute numbers may be of more practical usefulness than that of proportions. For example, as to be discussed in Sect. 4.3, the numbers of Chinese oldest-old aged $80+$ living alone (who may likely need care services) in 2010 increased by $233.2 \%$ compared to 1990 , in contrast to $21.8 \%$ increase in the proportion of oldest-old living alone among total population in the same period.

The statistical offices publish cross-tabulations of both proportions and absolute numbers based on the $100 \%$ census data, but these cross-tabulations only contain certain limited broad categories and do not have detailed information of households by types/sizes and contain very little information about elderly living arrangements. Thus, scholars rely on the data source of micro samples of the censuses to estimate the proportion distributions by detailed types of family households and elderly living arrangements, which are very useful for academic research and policy analysis. However, almost all of the previously published studies on family households and elderly living arrangements based on the census micro data included only proportion distributions, but did not contain detailed information about the cross-sectional and dynamic changes in absolute numbers. Our present study intends to contribute to this research field by estimating and discussing both detailed proportions and absolute numbers of family households by types/sizes and elderly population by living arrangements, based on the approach of integrated analyses on the census micro samples data and the official $100 \%$ cross-tabulations.

Note that it is not valid to simply multiply the detailed proportion distributions of family households and elderly living arrangements derived from the census micro sample data by the absolute numbers of the officially published very limited summary measures based on the $100 \%$ census data to estimate the corresponding detailed absolute numbers, as it would produce results which are not internally and logically consistent. Thus, to avoid the inconsistence, we apply the "BasePop" module of the ProFamy extended cohort-component model and its software program for households and elderly living arrangements projection (Zeng et al. 2014). Based on the detailed census micro samples data and the official $100 \%$ census data cross-tabulations of summary measures, the ProFamy "BasePop" module prepares the detailed $100 \%$ population distributions of households and living arrangements by household types/sizes, age/sex, co-residence and rural-urban residence in the census year as baseline for the family households projections, while ensuring the internal consistencies and accuracy. The ProFamy model and its technical modules (including BasePop) and procedures were described, numerically evaluated and discussed elsewhere (Zeng et al. 1998, 2014), and thus no need to be detailed here. 


\section{Changing family households, 1990-2010}

\subsection{Chinese family household size is steadily decreasing}

In 1990, four-person households constituted the largest share of all household categories by size, but it became the second largest in 2000 and the third in 2010 . The five-or-more-person households account for $33 \%$ of the total family households in 1990 but sharply declined to $22 \%$ in 2000 and to $17 \%$ in 2010 . Three-person households constituted the largest percentage share in both 2000 (30\%) and $2010(27 \%)$; whereas the two-person household became the second largest group of households in 2010 (23\%). Large households were no longer popular, namely, the six-or-more-person households constituted $15.4 \%$ in 1990, and decreased to only $8.1 \%$ in 2000 , and further down to $6.6 \%$ in 2010 (see Fig. 1).

The average family household size in China was 5.6 in 1930-1940 and 4.36 in 1982; it was reduced to 3.94 in 1990; further decreased to 3.45 in 2000 and then to 3.10 in 2010. Note that according to the Chinese census enumeration rules, the average family household sizes include the emigrants who left home for less than half a year for job-related reasons, and they were counted as homehousehold members; but these persons were not actually living in their home residence. Therefore, the actual average household size in China today would be even smaller than the published figures, if those who left home for less than half a year for finding a permanent job elsewhere were not counted as their hometownhousehold members. It is clear that Chinese family household size is steadily and substantially decreasing due to dramatically decreased fertility, the rapid industrialization, rise in education, and changes in people's attitudes, which tend to favor smaller family households.

Although Chinese family households maintain the typical Asian characteristics, namely, the three-generation extended family households remain a relatively large proportion of the household types (to be detailed in Sect. 3.5), Chinese family households in 2000-2010 were substantially smaller than those of many large Asian developing countries. For example, the average family household size in

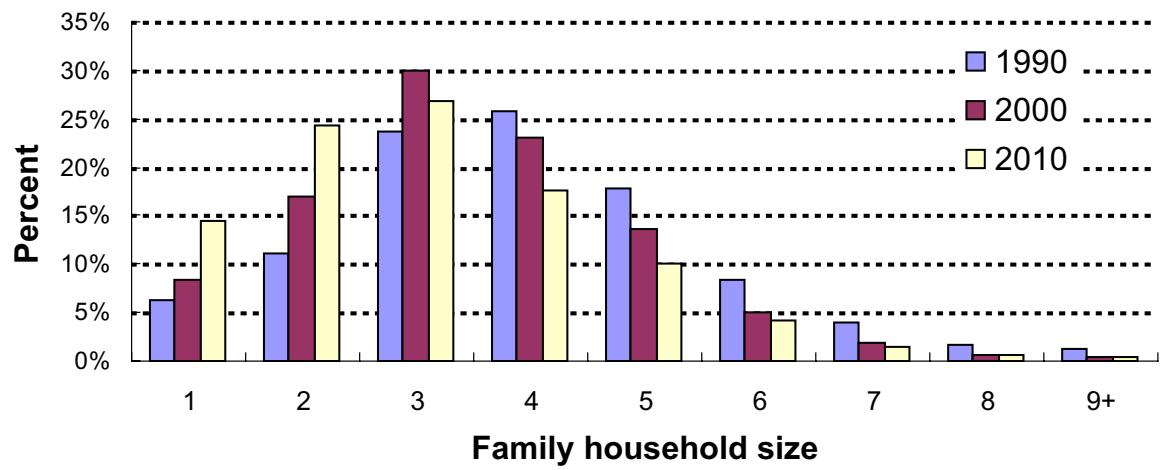

Fig. 1 Family household size distributions, rural-urban combined, 1990-2010, China 
India and Indonesia in 2010 was 4.91 and 3.90 (per the Indian and Indonesian censuses), which is 58.9 and 26.2 percent larger than that in China in the same year, respectively.

\subsection{Dramatically increased proportion of one-person and one-couple only households}

One-person households in 2010, 2000 and 1990 accounted for 14.5, 8.3 and 6.3 percent of all households, respectively, representing a 75.1 and 131.8 percent increase in 2010 compared to 2000 and 1990, respectively.

The one-couple only family households accounted for $17.7 \%$ of all households in 2010, which was 2.7 times as large as that in 1990, and 1.4 times as large as that in 2000 (see Table 1). The average annual rate of increase in the percent of one-couple only households was $8.6 \%$ in the period between 1990 and 2010. This dramatic increase is likely due mainly to considerably more elderly couples living without their children (to be discussed later) and many couples delaying childbearing in 2010 as compared to 2000 and 1990; the increasing number of young couples in the cities who choose to remain childless (i.e., the so-called "Double Income and No Kids") may also be a contributing factor. For example, based on the famous "Zero point index" surveys, the proportion of "Double Income and No Kids" family households in the largest Chinese cities of Beijing, Shanghai, Guanzhou and Wuhan increased from $1.1 \%$ in 1997 to $10.5 \%$ in 2004, and the average proportion among 20 Chinese cities (including middle and smaller size ones) was 6.5\% in 2008.

However, the dramatically increased percentages Chinese one-person and onecouple only households are still much lower than those in Western countries. For example, the one-person and one-couple only households in the United States in 2010 constitute 26.7 and 27.2 percent of the total number of households, being 1.84, and 1.54 times as high as the Chinese ones, respectively. The main reasons why the percentages of one-person and one-couple only households in China are still much lower than those in Western countries are threefold. First, many fewer Chinese remain never-married for life. Second, most Chinese couples, especially about half of the population who live in rural areas, had their first birth earlier than their Western counterparts and much fewer couples remain permanently childless. Third, as discussed in greater details later, unlike the elderly in the Western countries who mostly do not live with their adult children, most Chinese elderly, especially those who have no spouse, live with their children, and such a tradition remains in place although it is declining.

\subsection{Much faster increase in number of households than in population size}

Figure 2 shows that the number of Chinese family households increased by $45.1 \%$ in 2010 compared to 1990 , which is 2.5 times as large as that of the population growth (17.9\%) during the same period. Figure 2 also demonstrates that the relative difference between the increase of households and population size in later period 2000-2010 was much larger than that in earlier period 1990-2000. More 


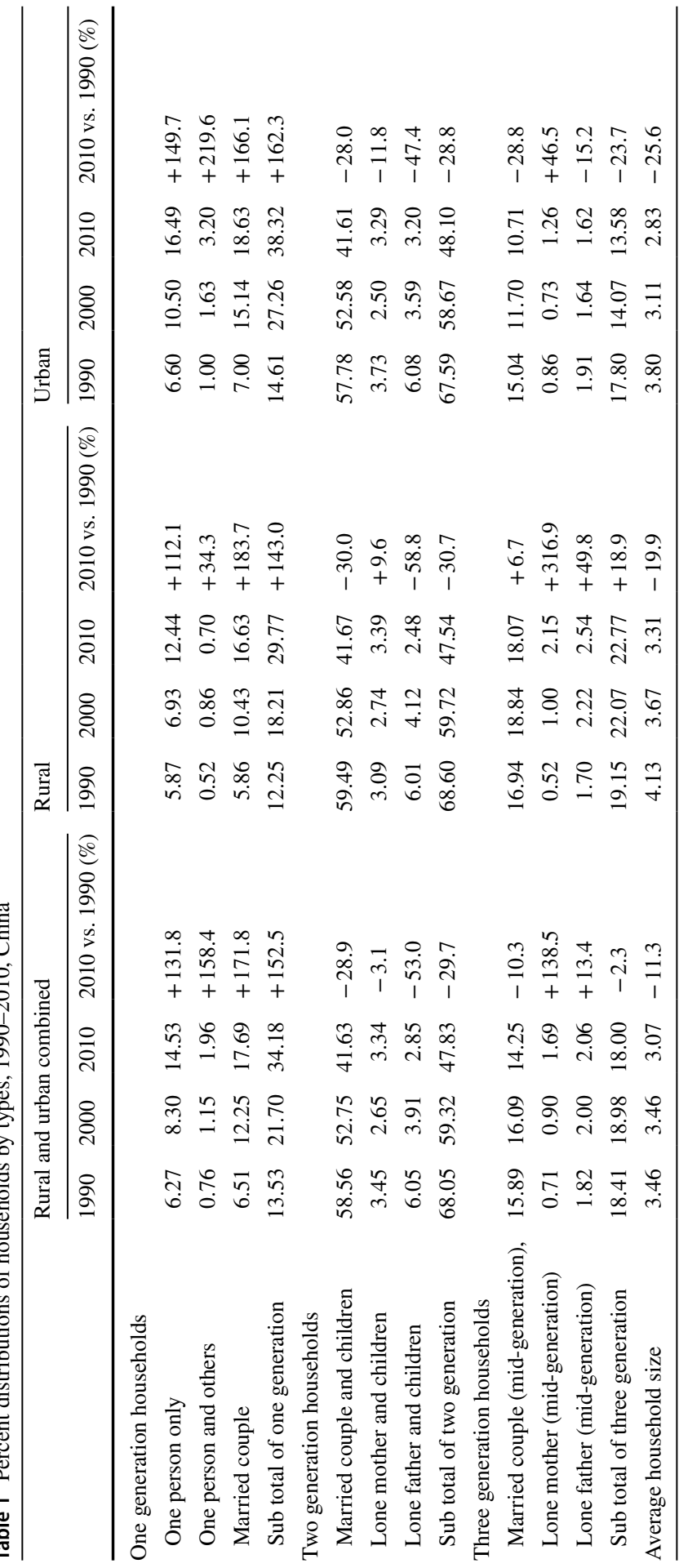




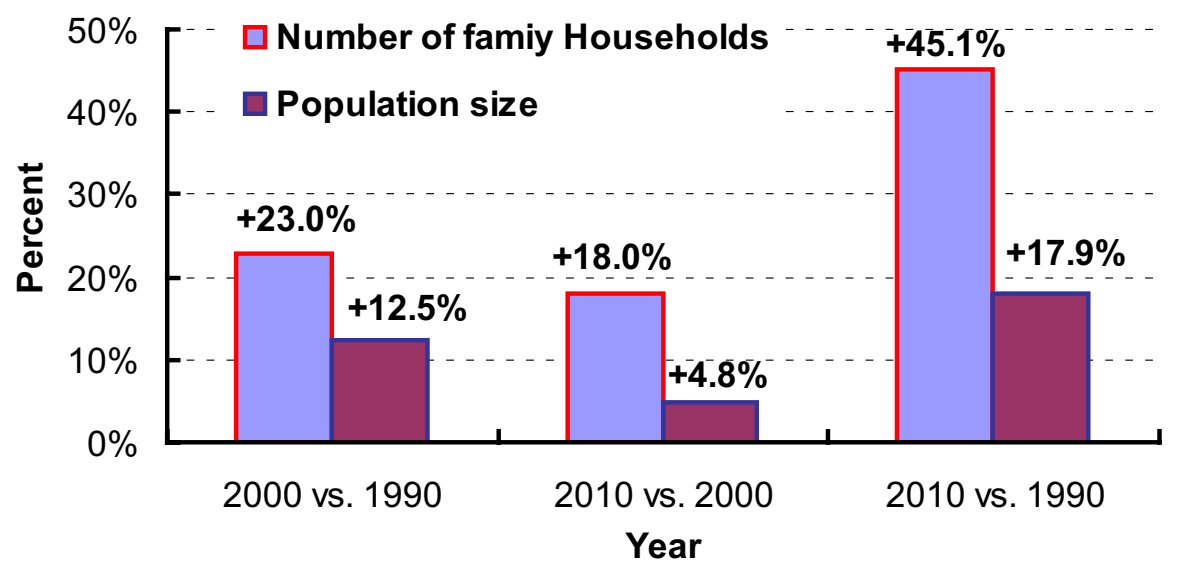

Fig. 2 Relative increases of number of households and population size, 1990-2010, China

specifically, the increase in the number of households was 3.8 times $(=18.0 \% / 4.8 \%)$ as large as that of population growth in 2000-2010, in contrast to the corresponding relative difference of 1.8 times $(23.0 \% / 12.5 \%)$ in $1990-2000$. The data shown in Fig. 2 clearly indicate that while population growth in China has slowed down substantially, the number of households is increasing rapidly because many Chinese people are forming one- or two-person and other kinds of small households.

The trends and pattern of much faster increase in number of households than the population growth have important implications in the current and future market demands for products and services, of which households (rather than individuals) are the consumption units, such as housing, home-based energy use, TV, refrigerators, washing machines, furniture and family-use vehicles. For example, there has been a rising consensus that households increase (rather than population growth) should be considered as one of the most important factors in analyses for homebased energy consumption (such as cooking, heating, cooling and private vehicles) and sustainable development (MacKellar et al. 1995; Liu et al. 2003). Even without population growth, energy consumption is driven by growing number of households resulting from smaller size of the residential units.

\subsection{Substantially decreasing percent of two-generation nuclear family households}

The proportions of nuclear family households of one-couple and children and single-parent and children households decreased by 28.9 and 33.7 percent respectively, from 1990 to 2010 (see Table 1). This substantial decrease in nuclear family households is due to the large increase in one-couple only and one-person households. The decreasing percentage of single-parent family households while the divorce rate in China is increasing (Wang et al. 2018; Fig. 1) may be due to that most divorces 
involve couples who have no children or whose children have already left home, increased remarriage rates and the decreasing widowhood rate.

\subsection{Changes in proportion of three-generation family households}

While nuclear family households are the mainstream in Chinese society today, extended family households with three generations also constituted a relatively large proportion: $18.41,18.98$, and 18.00 percent in 1990, 2000, and 2010, respectively (see Table 1). The three-generation family household was the second largest family household type in 2010, while the most popular one was the two-generation nuclear households, and the third and fourth were one-couple-only and one-person-only households.

Note that the proportion of three-generation family households in rural areas had increased by $18.9 \%$ in 2010 as compared to 1990 , but it had decreased by $23.7 \%$ in the urban areas in the same period, while the proportion of three-generation family households in rural and urban combined in slightly decreased by $2.3 \%$ in 1990-2010. We will discuss such interesting phenomenon and the dramatic rural-urban differentials in the Sect. 5.1.

\section{Dynamics of elderly living arrangements, 1990-2010}

Analysing the changes of elderly living arrangements would more directly and accurately reveal the changes in intergenerational co-residence between old parents and adult children than looking at only the proportions of three-generation versus nuclear family households as discussed above. Furthermore, we must pay special attention to the living arrangements of oldest-old aged 80+, who most likely need help of care in daily life and are increasing much faster than that of any other age groups. We, therefore, devote a substantial portion of this paper to analysing the dynamic changes in elderly living arrangements since 1990 and classify the elderly population into two broad groups of younger elders aged 65-79 and the oldest-old aged $80+$.

\subsection{Co-residence between old parents and adult children declined substantially}

As shown in Tables 2, 3 and 4, the proportions of elderly living with children (including children and grandchildren hereafter, unless otherwise specified) have declined substantially in both periods 1990-2000 and 2000-2010. In the same time, the majority of Chinese elderly still live with their children, because children are currently the major source of old age care in Chinese society. Note that the decrease among the young-olds (Table 3) were faster than that among the oldest-olds (Table 4). More specifically, the proportions of younger male and female elderly aged 65-79 who co-resided with children in 2010 was lower by 28.5 and 21.3 percent respectively as compared to 1990 (Table 3); and the corresponding figures of 


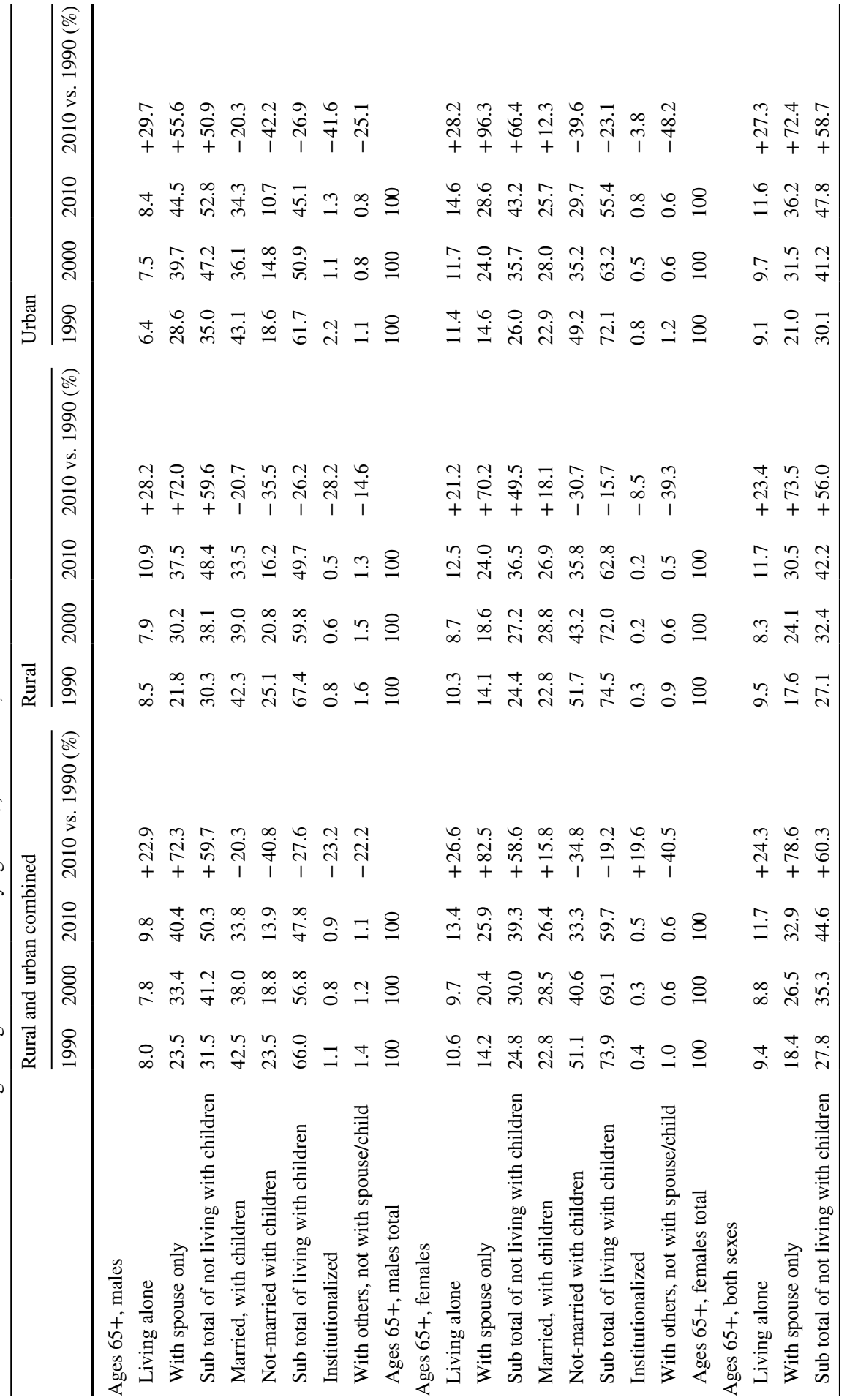




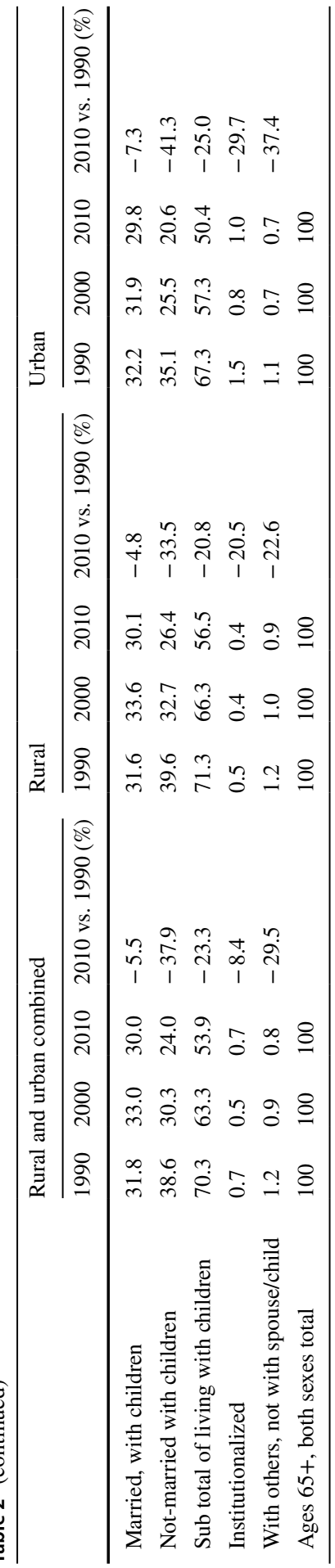




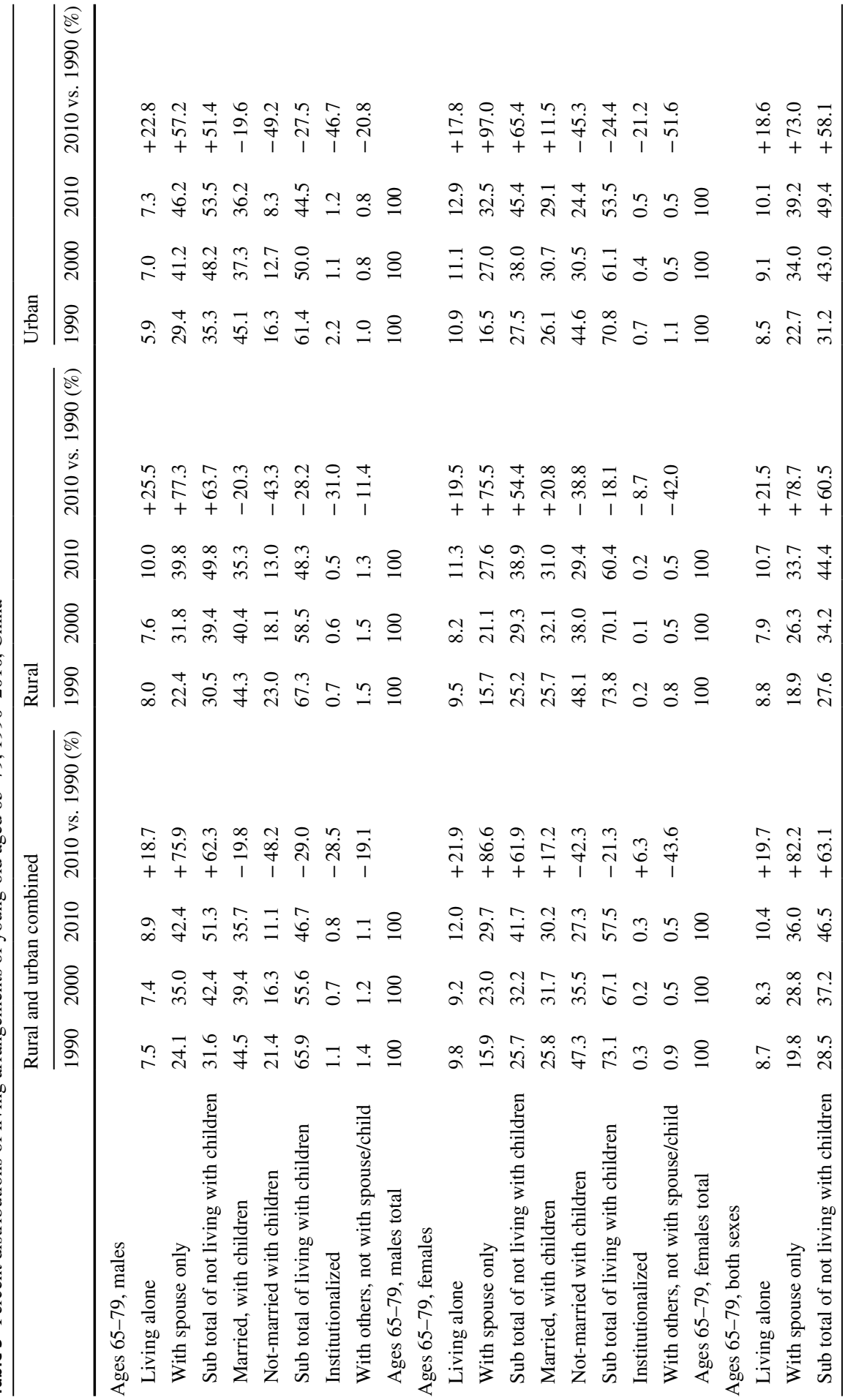




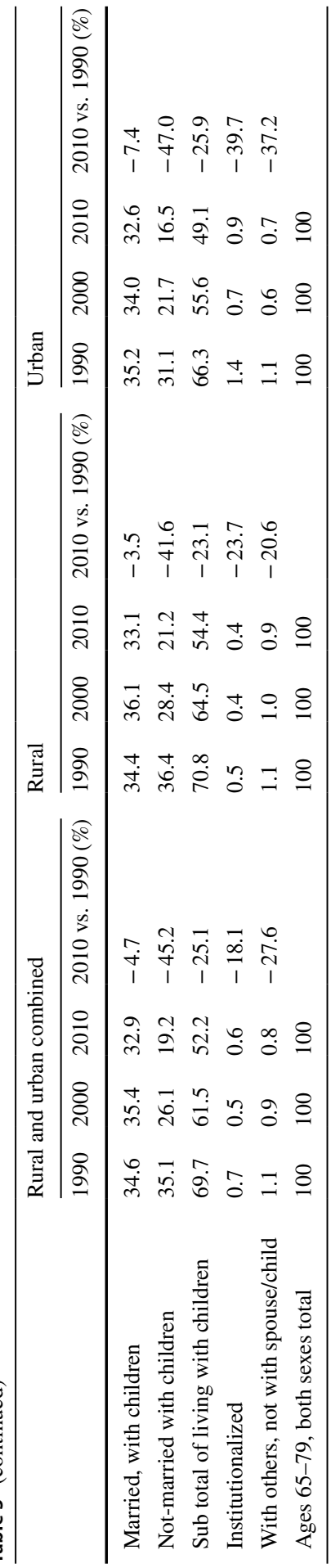




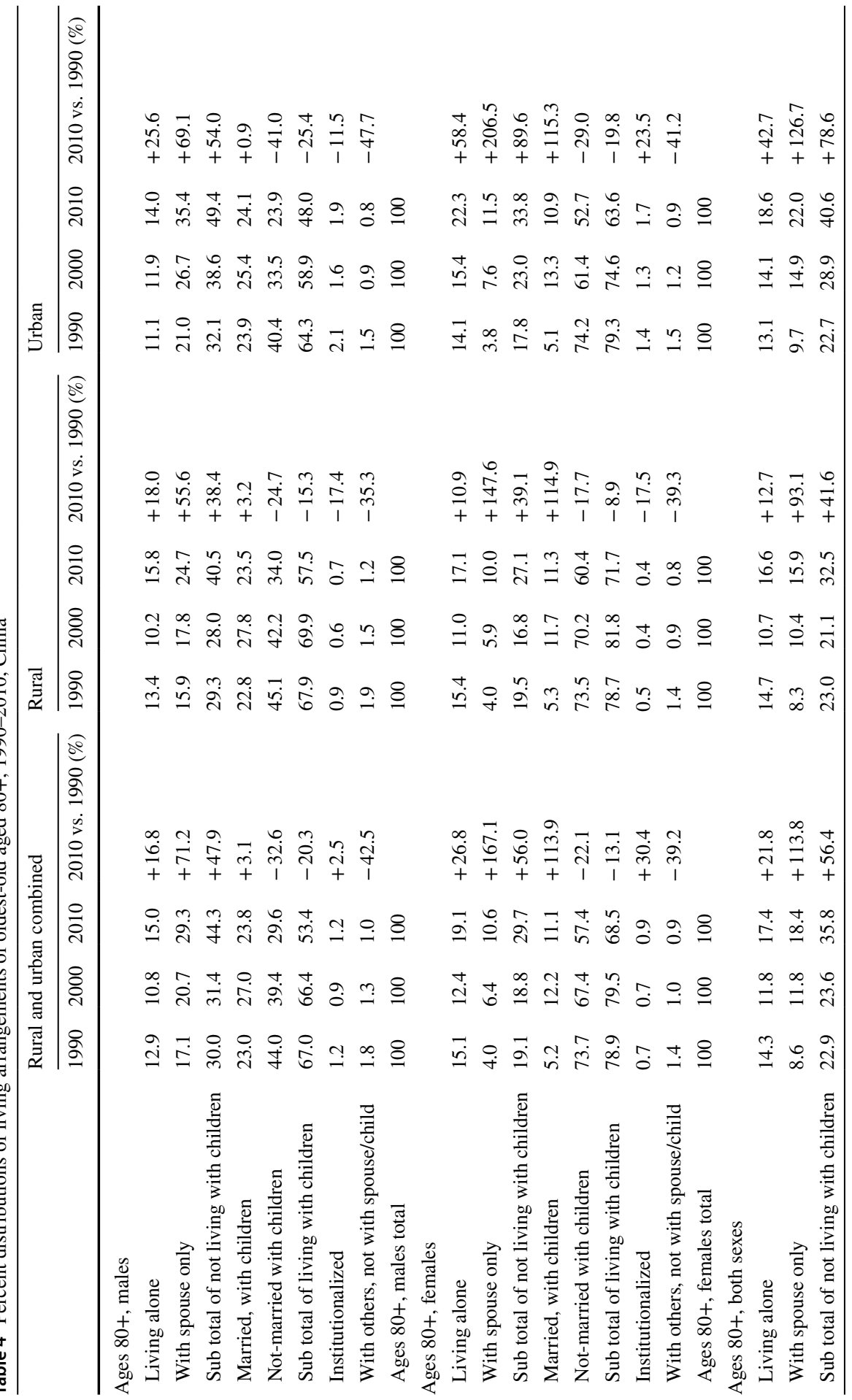




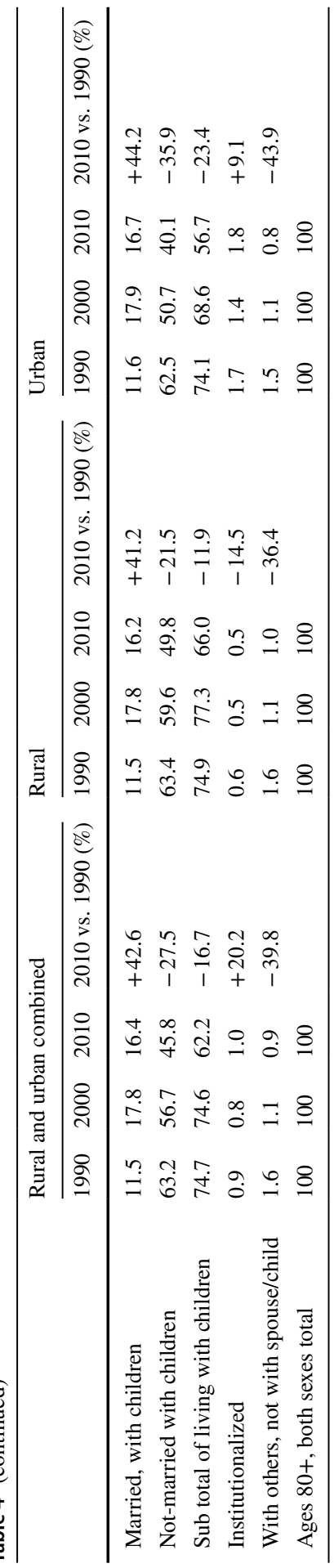


decrease among male and female oldest-old (aged 80+) were 20.3 and 13.1 percent (Table 4). Among the male and female elderly populations aged $65+$, the proportion of those living with children dropped by 27.6 and 19.2 percent respectively in 2010 as compared to 1990 (Table 2). These data indicate that the prevalence of the traditional co-residence between elderly parents and adult children has declined substantially from 1990 to 2010, and the decrease was considerably more profound among young-olds than among the oldest-olds, and the decrease was substantially faster among males than females. Such trends and patterns may be due to younger and healthier elderly parents' increasing preference to live independently, and due to more adult children migrated away from their elderly parents for job-related reasons. It is clear that the female elderly (either young-olds or oldest-olds) are much more likely to live with their adult children (see Tables 2, 3, 4) than male elderly; and this gender differentials have increased in 2000-2010 as compared to 1990. This is because elderly women are more likely to be widowed and economically dependent and they are also more likely prefer and to be requested by their children to live together to take care of grandchildren.

\subsection{Proportion of living alone and living with spouse only among Chinese elderly substantially increased}

The proportion of elderly aged 65+ who live alone has declined by $6.4 \%$ from 1990 to 2000 , but increased by $33.0 \%$ in 2010 compared to 2000 . In the 20 -year period from 1990 to 2010, the proportion of elderly living alone has increased by $24.3 \%$ (Table 2). The relative increase of young-olds who lived alone was substantially faster than that for the oldest-olds, and the relative increase of female young-old and female oldest-old who lived alone was substantially faster than that of their male counterparts (Tables 3, 4).

The relative increase in the proportion of elderly who lived with their spouse only for the oldest-olds (113.8\%) in the period of 1990-2010 was much faster than that for the young-olds $(82.2 \%)$, especially so for the female oldest-olds ( $167.1 \%$ increase) versus female young-old ( $86.6 \%$ increase). The large increase in the proportion of elderly who lived with their spouse only in 1990-2010 was likely because of the substantial decline in the proportion of elderly who lived with their adult children due to increase in preference for independent living, increased mobility of their children, decline in mortality of elders' spouses, and rise in remarriage rates among the elderly. The increase in remarriage rates among the elderly is a result of social reform and the progress of mate-matching services in the last two decades in China. The reform aimed to protect elders' rights, including the right to remarry, which in traditional Chinese society were often violated by the intervention of children and other family members. While the proportion of the elderly who live with a spouse only in China has increased substantially in the past two decades, it is still much lower than that in the Western countries, because the proportion of Chinese elderly who live with children is much higher than that in the Western countries (Zeng et al. 2013).

Note that both younger elderly women and oldest-old women are much more likely to be widowed and thus to live without a spouse, with children only or even 
to live alone (see Tables 3,4). On the other hand, elderly women are economically more dependent. Therefore, the disadvantages of women in marital life and independent family household living arrangements are substantially more serious than those of men at old ages, and the gender differentials tend to increase with age.

\subsection{The relative increases in absolute numbers versus proportions of elderly by living arrangements}

It is interesting to note that, while the proportions of elderly who live alone and live with a spouse only among elders aged $65+$ in 2010 has increased by 24.3 and 78.6 percent since 1990, respectively (see Table 2), the absolute numbers of elders aged $65+$ who lived alone and lived with a spouse only have increased by 134.7 and 237.3 percent in the same period (see Appendix Table 5). It is even more remarkable to note that the numbers of oldest-old who lived alone and lived with a spouse only have increased by 233.2 and 484.7 percent from 1990 to 2010 (see Appendix Table 7), in contrast, the increase in the proportions in the same period was 21.8 and 113.8 percent (see Table 4). The much larger relative increases in the absolute numbers of the elderly (especially the oldest-old) who live alone or with spouse only than the corresponding proportions are mainly due to the rapid population aging in China characterized by a rapid increase of the numbers of elderly especially the oldestolds as the later and larger cohorts become elderly and oldest-old (ref. discussions in Sect. 2). The policy makers and business managers need to draw special attentions to such trends of dramatic increase in the absolute numbers of elderly (especially the oldest-olds) who live alone or live with spouse only (rather than looking at the proportions only) in their analysis, so as to appropriately plan for the social service programs and commercial market products.

\section{The rural-urban differentials}

\subsection{Rural-urban differentials in family household structure}

The average sizes of family households in Chinese rural and urban areas in 2010 were 3.3 and 2.8, respectively; the average household size in urban area dropped by $25.6 \%$ from 1990 to 2010 , in contrast to the $19.9 \%$ decrease in the rural area in the same period (Table 1). As shown in Fig. 3, the major difference of the percentage distributions of households by size between rural and urban areas is that the percent of small households of 1 or 2-3 persons in urban area are much higher than those in rural areas, while the opposite was true for the larger household of 4-5 and 6+ persons. The rural-urban differences tend to be larger in the later years of 2010 and 2000 compared to 1990. The main factors for such substantial differentials of family household sizes between the Chinese urban and rural areas include the much lower fertility in urban than in rural areas, and the large rural-urban family structural differentials to be discussed below. 


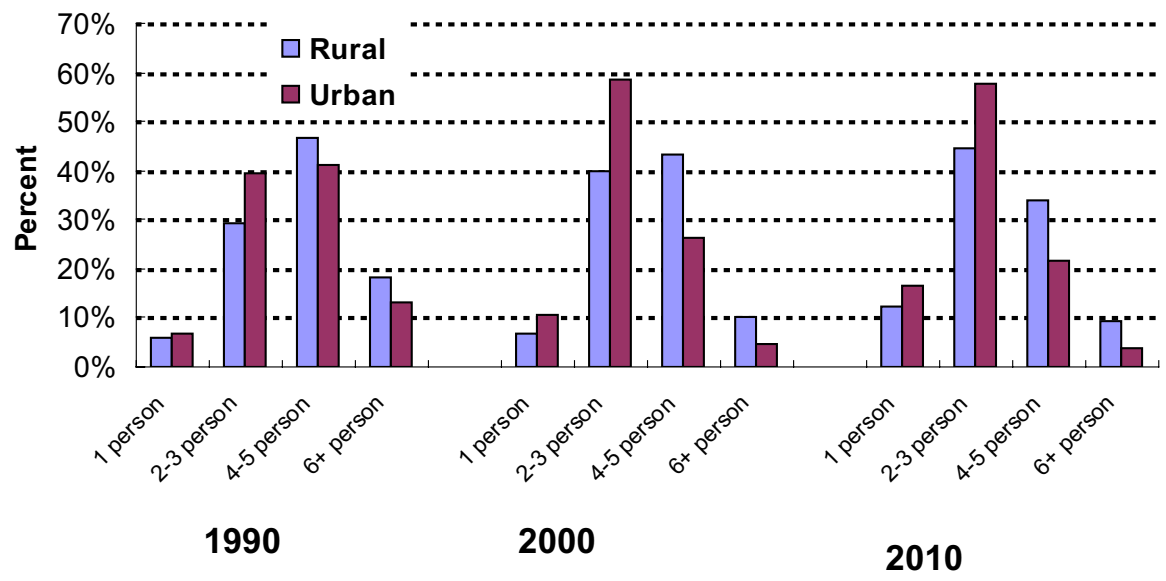

Fig. 3 Rural-urban comparisons of household size distributions, 1990-2010, China

The one-person households and one-couple only households were substantially less prevalent in rural areas than that in the urban areas as revealed in all three censuses conducted in 1990, 2000 and 2010 (see Table 1). The proportion of one-person only households has increased by $149.7 \%$ in the urban areas from 1990 to 2010 , as compared to $112.1 \%$ increase in the rural areas. The higher and faster increase of one-person households in the urban areas may be a result of a higher divorce rate and that more not-married elderly prefer to have independent living or shortage or mobility of children in the cities than that in the countryside.

The proportion of one person and other(s) households in the urban area more than tripled in 2010 (3.2\%) compared to 1990 (1.0\%), while it has increased by 34.3\% only in the rural areas. Data (not shown) indicate that almost all of the tremendous increase in proportion of households with one person and other(s) in 1990-2010 were from households with a reference person aged less than 65 . Thus, we believe that this is mainly due to the fact that much more young or middle-age urban residents who do not live with spouse and children but share an apartment with the roommate(s).

The three-generation family households constituted $22.8 \%$ in the rural areas in 2010 , in contrast to $13.6 \%$ in urban areas in the same year; these data indicate that the prevalence of three-generation family households in rural area was 1.7 times as high as that in the urban areas (see Table 1). It was interesting to note that, compare to 1990 , the proportion of three-generation family households in 2010 increased by $18.9 \%$ in rural area, while it was decreased by $23.7 \%$ in the urban area (Table 1).

Was the family household structure in the rural areas in China in 2010 more traditional than that in 1990? This seems unlikely because it is contradictory to the expected attitudes and behavior changes induced by the rapid socioeconomic development and the opening door to the outside world that have been occurring in China including rural and urban areas in the past four decades. Moreover, as shown in Table 2, the co-residence between old parents and adult children in rural areas has also declined substantially during the period of 1990-2010. Therefore, we believe that, while the 
proportion of two-generation nuclear family households has dropped substantially in rural areas (see Table 1), the considerable increase in the proportion of the three-generation family households in the rural areas in 2010 compared to 1990 was mainly due to the demographic effects of a sharp decline in fertility. More specifically, given that most rural elderly parents still live with one married child (although declining), the adult children who were born after the early 1970s and have much fewer siblings due to a large decline in fertility have a smaller chance of moving out of the parental home to form an independent nuclear family household (Zeng 1986, 1991), and thus resulted in the considerable structural increase in the proportion of three-generation households in rural China in 1990-2010. However, while rural fertility is still slightly above or around replacement level, fertility level in Chinese urban area declined to below replacement level in late 1970s and continued to decline or sustained at a very low level since then. As modeled and numerically simulated in Zeng (1986, 1991), if fertility continues to fall after reaching the replacement level, a further reduction in the birth rate will reduce the proportion of three-generation households because it will be impossible for some elderly parents to live with their married child even if they wish to do so due to the shortage of children. Of course, in addition to such impacts of far-below-replacement fertility level in the urban areas, largely changing attitudes concerning intergenerational co-residence and increasing job mobility of adult children are also the major factors contributing to substantially decreased proportion of threegeneration households in urban China in 2010 compared to 1990.

Clearly, while family households have been radically changing in both rural and urban areas, rural Chinese family households are more traditional than are their urban counterparts, because the socio-economic development level and changes in people's attitudes about multi-generational co-residence is substantially slower in rural than in urban areas, as well as due to the different demographic effects of fertility decline between rural and urban areas.

\subsection{Rural-urban differentials in elderly living arrangements and its dynamic changes}

The proportions of elderly men who live with children in rural and urban areas in 2010 were 49.7 and 45.1 respectively, and the corresponding figures for women were 62.8 and 55.4, respectively (see Table 2). Obviously, the rural elderly are more likely to live with their children than their urban counterparts do. Moreover, the proportion of elderly living with children has declined at a slower speed in rural $(20.8 \%)$ than in urban areas (25.0\%) from 1990 to 2010.

The proportion of urban elderly women living alone is higher than that in rural areas by 2.1 percentage points. But the proportion of urban elderly men living alone is 2.5 percentage points lower than that in rural areas (see Table 2). In the urban area, there was a $25.6 \%$ increase of male oldest-old who lived alone, in contrast to $18.0 \%$ of increase of rural male oldest-old who lived alone between 1990 and 2010 (Table 4). In 2010, about one-fifth of female oldest-old living alone, representing a 58.4\% increase compared to that in 1990 in the urban areas, in contrast to $15.4 \%$ of female oldestold living alone in 2010 with a $10.9 \%$ increase in the rural areas in the period of 
1990-2010 (Table 4). The rural-urban and gender differences in the proportions of oldest-old living alone are enormous, and the largely increased female oldest-old living alone in urban areas deserve attentions from the government and society.

The proportions of urban elderly men and women who lived with a spouse only in 2010 were higher than those of their rural counterparts by 7.0 and 4.6 percentage points respectively, and the higher widowhood rates and lower remarriage rates in rural areas than in urban areas may have contributed to this phenomenon.

Tables 5, 6 and 7 in the Appendix demonstrated the rural-urban differences in relative increases of absolute numbers of old adults by living arrangements, which are dramatically larger than the rural-urban difference in changes in the proportions of the different living arrangements of elderly presented in Tables 2, 3 and 4.

\section{Conclusions}

This article presents analyses on dynamics of family households and elderly living arrangements in China mainly based on the micro data of 2010, 2000 and 1990 censuses. We demonstrate and discuss the trends and rural-urban differentials of largely declined household size, quickly increasing one-person and one-couple-only households, substantially increased proportions of elderly living alone or with spouse only. It is strikingly interesting that proportion of three-generation family households increased by $18.9 \%$ in rural area but decreased by $23.7 \%$ in urban areas in 2010 compared to 1990, due to rural-urban differences in demographic effects of large fertility decline and socioeconomic/attitude changes. We also present and discuss two interesting demographic phenomenon which are relatively overlooked in the literature. First, increase in number of households is much larger than population growth, due to shrinking of the household, decompositions of larger families into smaller ones, and very much slowed-down population growth. Second, increases in numbers of elderly (especially oldest-old) who live alone or with spouse only are dramatically larger than the increase in the corresponding proportions, due to the effects of rapid population aging, while later and larger birth cohorts become old. Such trends have important implications for the analyses on the current and future market demands of the products and services, of which households are the consumption units, such as home-based energy use, housing, TV, refrigerators, washing machines, furniture, family-use vehicles and health care services. We recommend that the studies on home-based energy use and sustainable development should be based on analyses of family household dynamics rather than population growth.

Acknowledgements This research is supported by National Natural Sciences Foundation of China (71490732).

\section{Appendix}

See Tables 5, 6 and 7. 


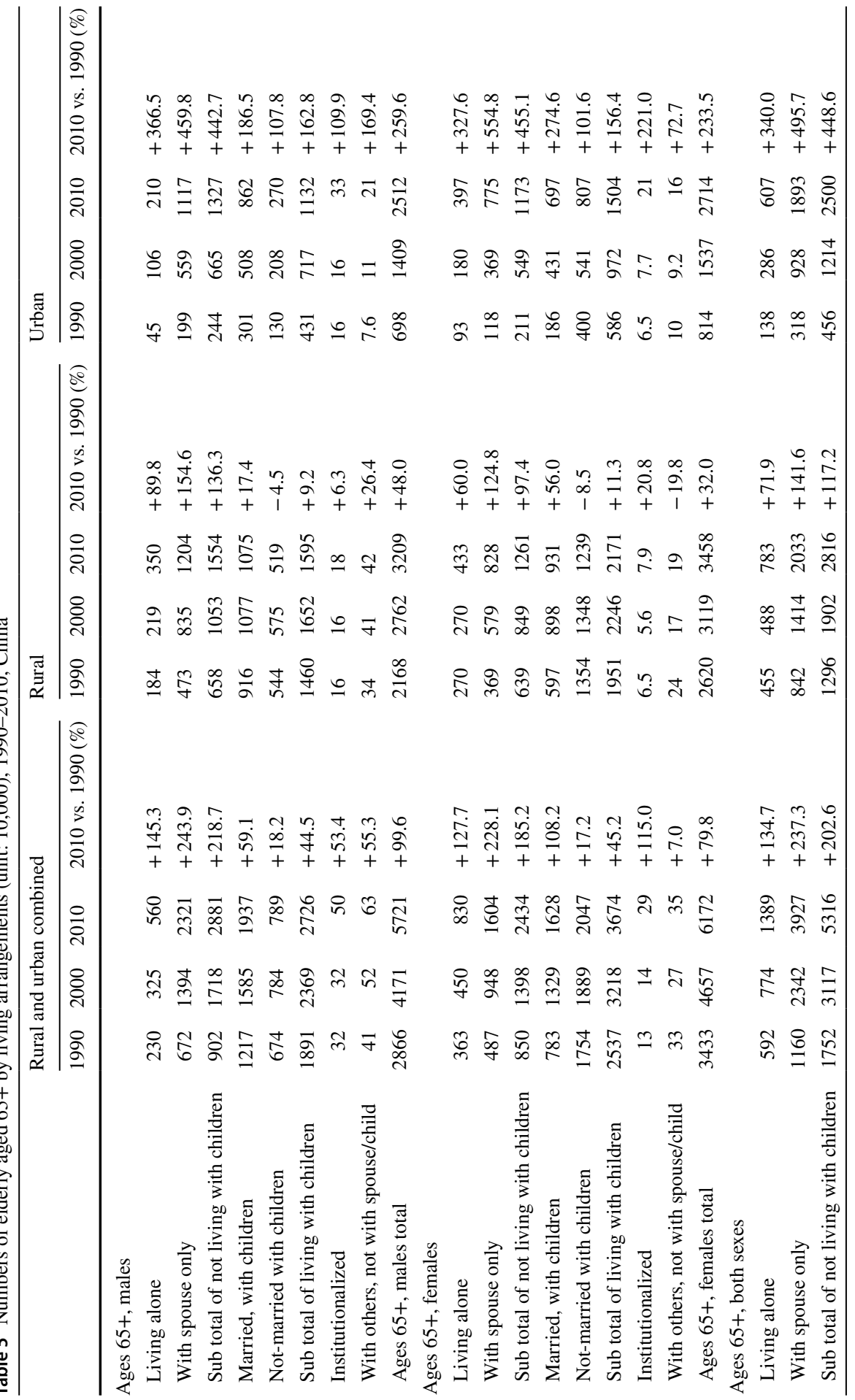




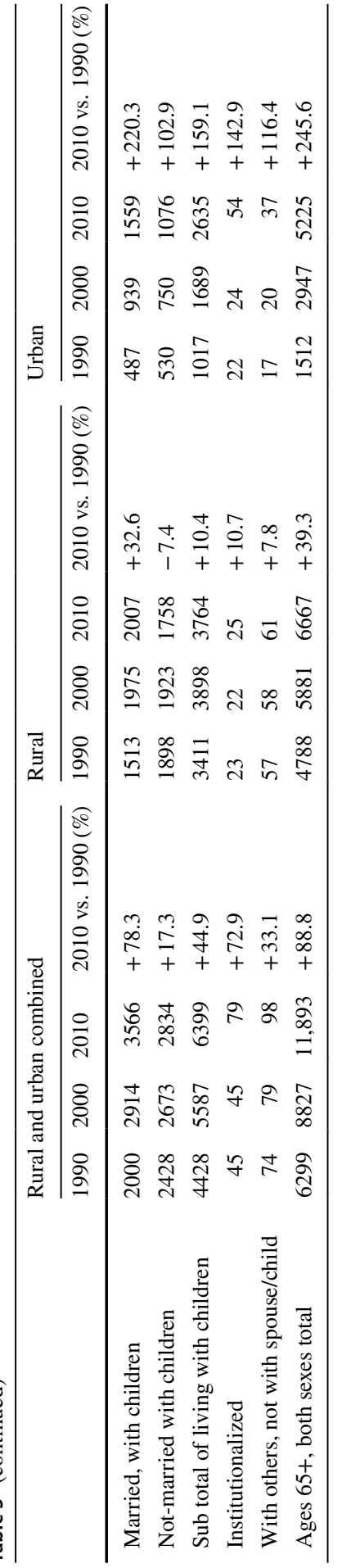




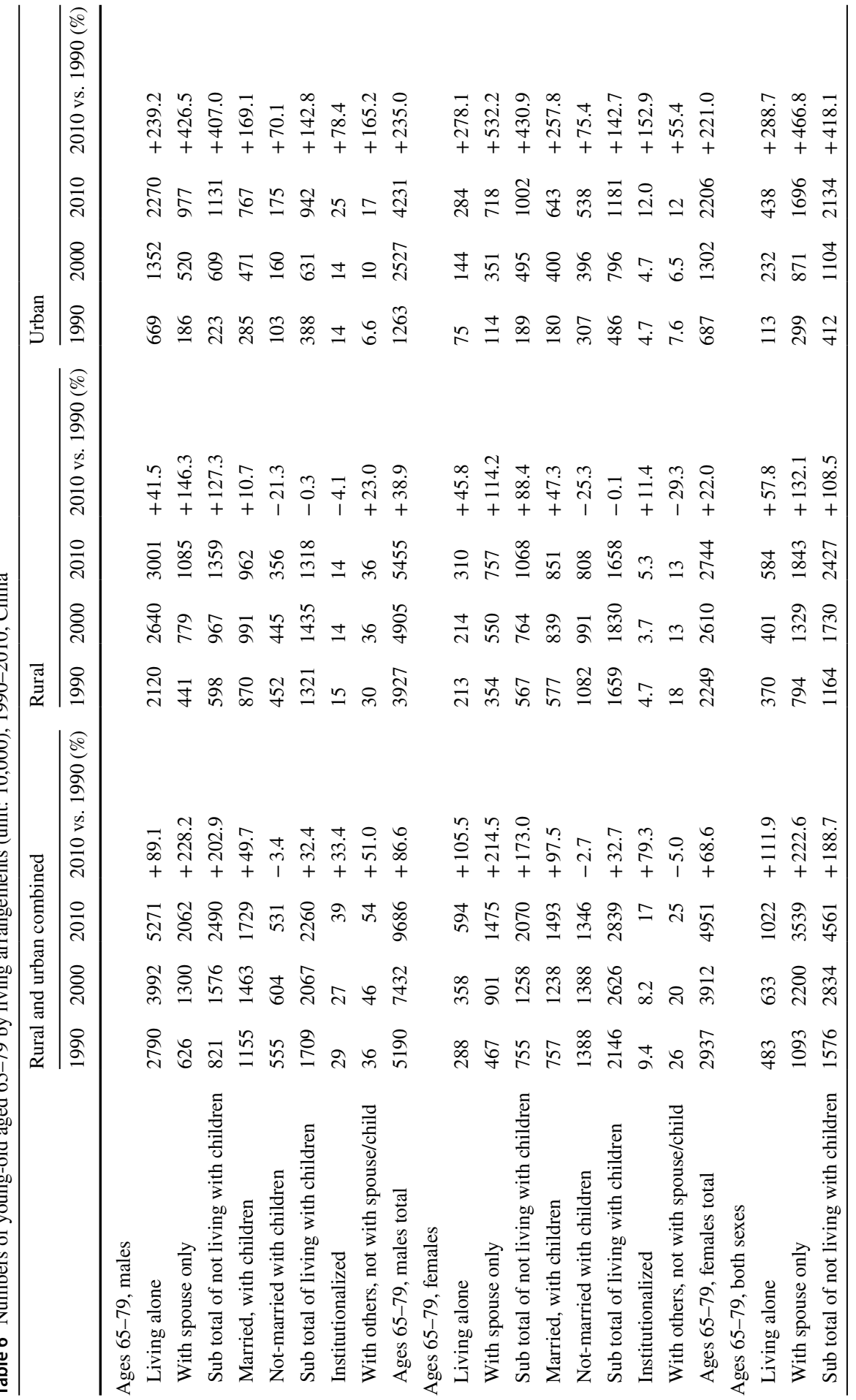




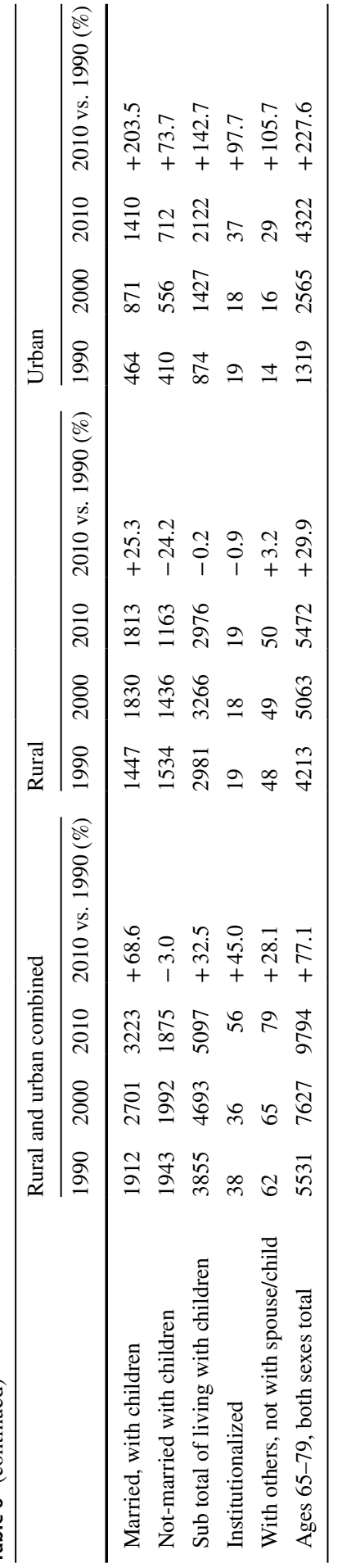




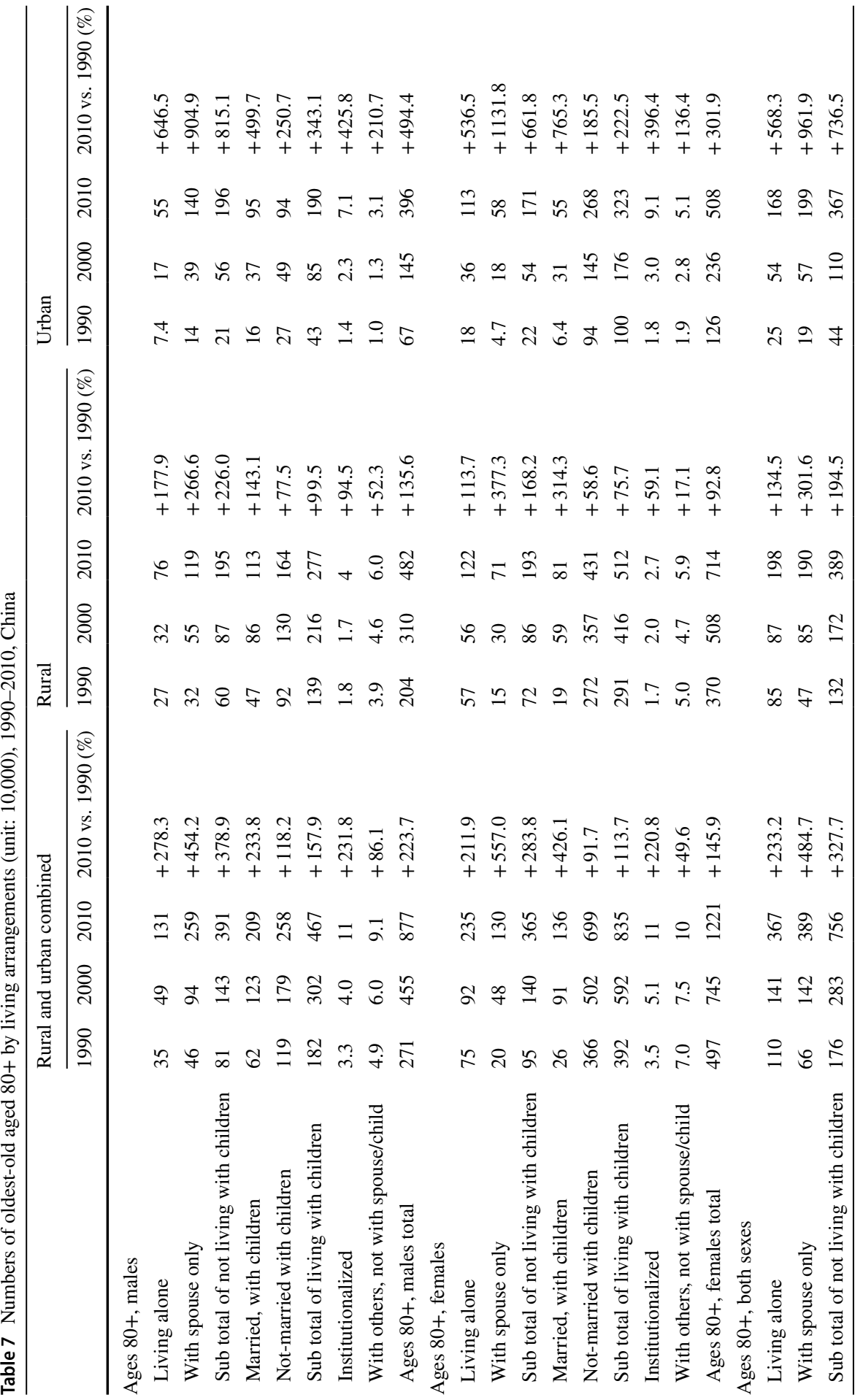




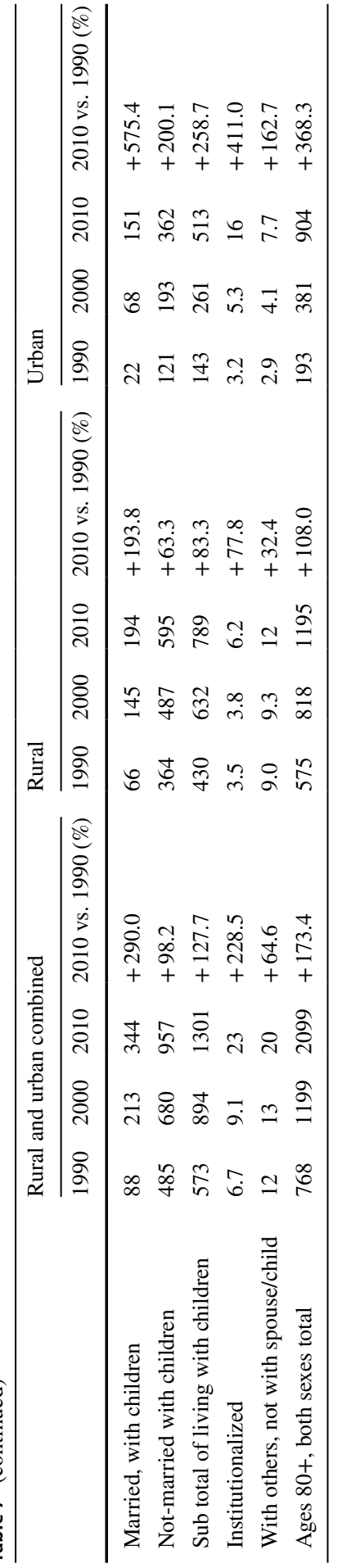




\section{References}

Banister, J., Bloom, D. E., \& Rosenberg, L. (2010). Population aging and economic growth in China. Harvard University Program on the Global Demography of Aging Working Paper No. 53. http://www.hsph. harvard.edu/pgda/working.htm. Accessed 20 July 2013.

Cai, Y. (2013). China's new demographic reality: Learning from the 2010 census. Population and Development Review, 39(3), 371-396.

Chen, X., \& Silverstein, M. (2000). Intergenerational social support and the psychological well-being of older parents in China. Research on Aging, 22(1), 43-65.

Cheung, A., \& Yeung, W. J. (2013). Temporal-spatial patterns of one-person households in China, 19822005 (under review in Demographic Research). In Paper presented at 2013 PAA meeting, Boston.

Coale, A. J. (1984). Rapid population change in China, 1952-1982. Washington DC: National Academy Press.

Cui, H., Lan, X., \& Li, R. (2013). Evaluation of the accuracy of the 2010 census. Research on Population, 1, $10-21$.

Fan, C. C. (2002). Population change and regional development in China: Insights based on the 2000 census. Eurasian Geography and Economics, 43(6), 425-442.

Guo, Z. (2008). Analyses of the Chinese household changes. China Population Science, 3, 2-10.

Hu, Z., \& Peng, X. (2014). Household changes in contemporary China: An analysis based on census data. Sociological Studies, 3, 145-166.

Kannisto, V. (1986). Features of the 1982 China census from international standpoint. In C. Li (Ed.), A census of one billion people. Papers for international seminar on China's 1982 population census (pp. 37-52). Boulder, Colorado: Westview Press.

Lavely, W. (2001). First Impressions from the 2000 Census of China. Population and Development Review, 27(4), 755-769.

Liu, J., Daily, G. C., Ehrlich, P. R., \& Luck, G. W. (2003). Effects of household dynamics on resource consumption and biodiversity. Nature, 421(6922), 530-533.

MacKellar, F. L., Lutz, W., Prinz, C., \& Goujon, A. (1995). Population, households, and CO2 emissions. Population and Development Review, 21(4), 849-865.

Pei, X., \& Pillai, V. K. (1999). Old age support in China: The role of the state and the family. International Journal of Aging and Human Development, 49(3), 197-212.

Wang, Y. (2006). Analyses of the Chinese household structure. China Social Science, 1, 96-108.

Wang, Y. (2013). An analysis of the changes in China's urban and rural family structures: Based on 2010 census data. China Social Science, 12, 60-77.

Wang, Y. (2014). Household type of the elderly in the rural and urban China. China Population Science, 34(1), 20-32.

Wang, F., Shen, K., \& Cai, Y. (2018). Household change and intergenerational transfers in China: What lies ahead? In N. N. Eberstadt (Ed.), China's impending changes in family structure: Dimensions and implications. Washington DC: AEI Press.

Yeung, W. J., \& Xu, Z. (2012). Economic stress, quality of life, and mortality rates among the oldest old in China. Social Indicators Research, 108, 131-152.

Zeng, Y. (1986). Changes in family structure in China: A simulation study. Population and Development Review, 12, 675-703.

Zeng, Y. (1991). Family dynamics in China: A life table analysis. Wisconsin: The University of Wisconsin Press.

Zeng, Y., Land, K. C., Gu, D., \& Wang, Z. (2014). Household and living arrangement projections: The extended cohort-component method and applications to the U.S. and China. New York: Springer.

Zeng, Y., Land, K. C., Wang, Z., \& Gu, D. (2013). Household and living arrangements projections at the sub-national level: An extended cohort-component approach. Demography, 50, 827-852. https://doi. org/10.1007/s13524-012-0171-3.

Zeng, Y., Vaupel, J. W., \& Zhenglian, W. (1998). Household projection using conventional demographic data. Population and Development Review, Supplementary Issue: Frontiers of Population Forecasting., 24, 59-87.

Zeng, Y., \& Wang, Z. (2003). Dynamics of family and elderly living arrangements in China: New lessons learned from the 2000 census. The China Review, 3(2), 95-119.

Zhang, Y. (2013). Household living, health and care arrangement of Chinese elderly: Based on the sixth census data. Jiangsu Social Science, 1, 57-65. 
Zhang, G., \& Zhao, Z. (2006). Reexamining China's fertility puzzle: Data collection and quality over the last two decades. Population and Development Review, 32(2), 293-321.

Zhao, Z. (2011). Reflections on China's recent population statistics and current demographic situation. Chinese Cross Currents, 8(3), 44-56.

Zhao, Z., \& Chen, W. (2011). China's far below-replacement fertility and its long-term impact: Comments on the preliminary results of the 2010 census. Demographic Research, 25(26), 819-836.

Zhou, C. (2013). Characteristics of family structure change and their implications: Based on the fifth and sixth census of China. Journal of Nanjing Population Management College, 4, 3-8.
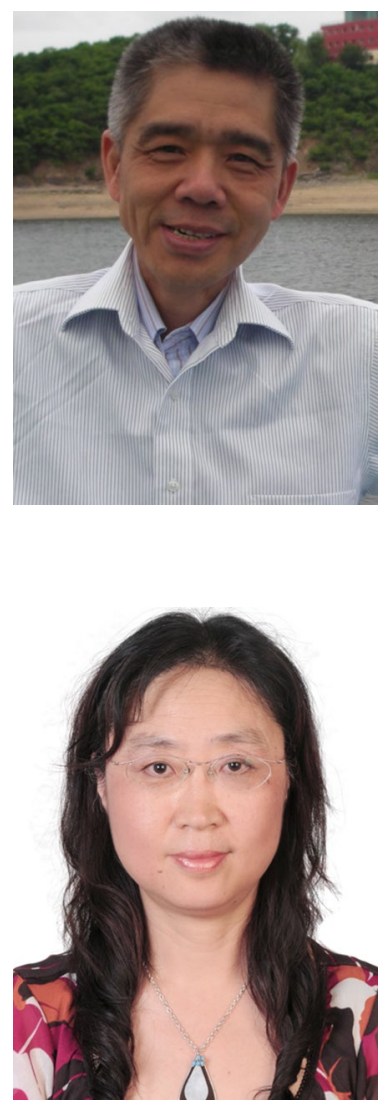

Dr. Yi Zeng received PhD degree from Brussels Free University in 1986 and had post-doc study at Princeton University in 1986-1987. $\mathrm{He}$ is a Professor at National School of Development and Chief Scientist of Raissun Institute for Advanced Studies, Peking University. He is a Professor at the Center for Study of Aging and Human Development and Geriatric Division of School of Medicine, Duke University. He is Distinguished Research Scholar of the Max Planck Institute for Demographic Research in Germany, and a foreign member of the Royal Netherlands Academy of Arts and Sciences. His main research interests are population healthy aging, methods and applications in family household projections, population policies, and effects of genes-environmental interaction of health outcomes. Up to Feb. 2018, he has had 154 professional articles written in English published internationally in academic journals or as book chapters. He has had 143 professional articles written in Chinese and published in China. He has published twenty-seven academic books, including ten books written in English.

Dr. Zhenglian Wang graduated from Department of computer science of Peking University in 1982 and received her $\mathrm{PhD}$ degree in Health Science (Medical Demography) of Medical School of the University of Southern Denmark in May 2001. She is a Senior Research Scientist at Center for Population Health and Aging of Population Research Institute at Duke University and a Research Fellow at China Population and Development Research Center. Her main research interests are population and family household projections, estimates, market research, population aging, and software development. She has expertise and been working extensively on ProFamy extended cohort-component method, database and software development for family households, living arrangements and consumption projections. She has published dozens of research articles. 


\section{Affiliations}

\section{Yi Zeng ${ }^{1,2}\left({ }^{10} \cdot\right.$ Zhenglian Wang $^{3}$}

1 Center for Healthy Aging and Development Studies and Raissun Institute for Advanced Studies, National School of Development, Peking University, Beijing, China

2 Center for the Study of Aging and Human Development and Geriatric Division of Medical School, Population Research Institute, Duke University, Durham, USA

3 Center for Population Health and Aging of Population Research Institute at Duke University, China Population and Development Research Center, Beijing, China 